\title{
COMBINED SUPPRESSIVE EFFECT OF CARDIOPULMONARY BYPASS AND AGING ON CELL-MEDIATED IMMUNITY
}

Kouichi Hisatomi, MD, Akira Kobayashi, MD, Yukinori Moriyama, MD, Shinji Shimokawa, MD, Hitoshi Toyohira, MD, and Akira Taira, MD, Kagoshima, Japan

The suppressive effect of cardiopulmonary bypass (CPB) on cell-mediated immunity has been investigated in patients after cardiac surgery. ${ }^{1,2}$ Immunity also reportedly declines with aging. ${ }^{3}$ With the recent progress in cardiac surgery, more elderly patients become surgical candidates. ${ }^{4}$ In this article, we examined the effect of CPB on cell-mediated immunity in elderly patients compared with younger patients.

Thirty male patients underwent elective coronary artery bypass grafting under same condition (anesthesia, CPB circuit, cardioplegia, oxygenator) and were divided into two equal groups by operative age. Mean age was 56.3 years (range 41 to 66 years) in group I and 74.1 years (range 72 to 81 years) in group II. The patients did not receive steroids or homologous blood transfusions during or after the operation. Clinical data of both groups were matched according to the preoperative New York Heart Association class and CPB time. None had perioperative myocardial infarction or infection. Peripheral blood samples were taken before the operation and on postoperative days (POD) 1, 3, and 7. The natural killer (NK) cell activity was measured by cytotoxity against the ${ }^{51} \mathrm{Cr}$ labeled K562 cells and expressed as percent cytolysis. Cytotoxic T-cell line was used for measurement of interleukin-2 (IL-2) production. The standard level (mean \pm standard deviation) of NK-cell activity (50:1) in men is $49 \% \pm 11 \%$ and the $\mathrm{IL}-2$ production range is 15 to 25

From the Second Department of Surgery, Faculty of Medicine, Kagoshima University, Kagoshima, Japan.

Received for publication Dec. 16, 1996; accepted for publication Jan. 22, 1997.

Address for reprints: Kouichi Hisatomi, MD, Second Department of Surgery, Faculty of Medicine, Kagoshima University, 8-35-1 Sakuragaoka, Kagoshima 890, Japan.

J Thorac Cardiovasc Surg 1997;114:140-1

Copyright (C) 1997 by Mosby-Year Book, Inc.

$0022-5223 / 97 \$ 5.00+0 \quad \mathbf{1 2 / 5 4 / 8 0 5 5 0}$
$\mathrm{U} / 5 \times 10^{5}$ cells. Data (mean \pm standard error) were analyzed by the two-way repeated-measures analysis of variance (ANOVA). Intergroup comparisons were performed with the use of the unpaired $t$ test or the MannWhitney $U$ test, as appropriate.

Preoperative and postoperative levels of NK-cell activity (percent) and IL-2 production (U/5 $\times 10^{5}$ cells) are shown in Table I. No significant intergroup differences were observed in NK-cell activity and IL-2 production before the operation. NK-cell activity was suppressed on POD 1 and returned to the preoperative level by POD 7 in group I. In group II, this response was similar on POD 1 but more suppressed on POD 3 and POD 7. Recovery of NK-cell activity was significantly delayed in group II on POD 7 ( $p<0.01$; ANOVA: $p$ [group] $=0.0251, p$ [time] $<0.0001, p$ [interaction] $=0.0033$ ). IL-2 production showed a similar tendency, that is, deeply suppressed on POD 1 in both groups and more suppressed in group II on POD 3 and POD $7(p<0.01$; ANOVA: $p$ [group] $=$ $0.0113, p$ [time] $<0.0001, p$ [interaction] $<0.0001$ ).

The age-associated decline in immune function is difficult to assess. However, in cardiac transplantation, a postoperative decline in immune responsiveness with aging has recently been recognized; the rejection rate in elderly patients ( $>60$ years) was significantly less than in younger patients, but elderly patients were more likely to die of postoperative infections or malignancy. ${ }^{5}$ Preoperatively, our results did not show intergroup difference in functional status on the basis of cell-mediated immunity, but they suggest that the response to CPB was more prolonged in elderly patients.

\section{REFERENCES}

1. Hisatomi K, Isomura T, Kawara T, Yamashita M, Hirano A, Yoshida $\mathbf{H}$, et al. Changes in lymphocyte subsets, mitogen responsiveness, and interleukin-2 production after cardiac operations. J Thorac Cardiovasc Surg 1989;98:580-91.

2. Nguyen DM, Mulder DS, Shennib H. Effect of cardiopulmo-

Table I. Immunologic data from younger or elderly patients having cardiac operations

\begin{tabular}{lcccc}
\hline & Preop. & $P O D 1$ & $P O D ~ 3$ & $P O D ~ 7$ \\
\hline NK-cell activity (\%) & & & & \\
$\quad$ Group I & $46.2 \pm 5.3$ & $12.9 \pm 2.7$ & $30.8 \pm 4.6$ & $43.8 \pm 3.8$ \\
$\quad$ Group II & $45.8 \pm 4.0$ & $9.2 \pm 1.6$ & $17.3 \pm 2.8^{*}$ & $23.2 \pm 2.1 \dagger$ \\
IL-2 production (U/5 $\times 10^{5}$ cells) & & & & \\
$\quad$ Group I & $23.6 \pm 5.2$ & $2.1 \pm 0.3$ & $14.8 \pm 3.6$ & $23.3 \pm 4.4$ \\
$\quad$ Group II & $21.3 \pm 3.7$ & $2.2 \pm 0.3$ & $5.7 \pm 3.4 \dagger$ & $11.2 \pm 3.5 \dagger$ \\
\hline
\end{tabular}

Preop., Preoperative; $P O D$, postoperative day; $N K$, natural killer; $I L-2$, interleukin-2.

${ }_{p}^{*} p<0.05$.

$\dagger p<0.01$. 
nary bypass on circulating lymphocyte function. Ann Thorac Surg 1992;53:611-6.

3. Fernandez LA, MacSween JM, Langley GR. Lymphocyte responses to PHA: age-related effects. Immunology 1976;31: $583-7$.

4. Salomon NW, Page US, Bigelow JC, Krause AH, Okies JE,
Metzdorff MT. Coronary artery bypass grafting in elderly patients. J Thorac Cardiovase Surg 1991;101:209-18.

5. Bull DA, Karwande SV, Hawkins JA, Neumayer LA, Taylor $\mathrm{DO}$, Jones $\mathrm{KW}$, et al. Long-term results of cardiac transplantation in patients older than sixty years. J Thorac Cardiovasc Surg 1996;111:423-8.

\title{
AORTIC ROOT ENDOSCOPY IN VALVE-SPARING OPERATIONS
}

\author{
Tsuyoshi Itoh, MD, Satoshi Ohtsubo, MD, Kojiro Furukawa, MD, and Hiroaki Norita, MD, Saga, Japan
}

Reconstructive operations on the aortic root have been revolutionized since a valve-sparing procedure was demonstrated to be a viable alternative to the conventional method of replacement with a composite valved graft. The new procedure aims to replace diseased aortic wall while preserving the native aortic valve and anulus. In 1992, David and Feinde ${ }^{1}$ reported original results with successful valve-sparing surgery by reimplanting the aortic valve in a tubular Dacron graft (reimplantation). Sarsam and Yacoub ${ }^{2}$ proposed a different technique of restoring the normal geometry to the aortic root, using a tailored Dacron graft (remodeling). Both operations require sophisticated techniques with an accurate anatomic understanding of the diseased aortic root. Although mathematical estimation based on the normal geometry of the aortic root is informative, ${ }^{3,4}$ several adjustments to the suture line may be required to decrease persistent aortic insufficiency when considering individual anatomic differences. An intraoperative macroscopic evaluation of the repaired aorta is not always accurate, because once the root has been opened, the aortic cusps are released from perfusion pressure and the root loses its tension and strain. The natural configuration of the root is thus manipulated, and recognizing any malcoaptation or overstretching becomes difficult. A reliable measure is required to cope with the diversity in the anatomic characteristics of a diseased aorta. This article reports the result of successful aortic valve-sparing surgery performed with the use of endoscopic guidance.

To date, we have successfully performed aortic root repair in five cases in which aortic root endoscopy was introduced to observe the valves during the operations.

From the Department of Thoracic and Cardiovascular Surgery, Saga Medical School, Saga, Japan.

Received for publication Nov. 25, 1996; accepted for publication Dec. 31, 1996.

Address for reprints: Tsuyoshi Itoh, MD, Department of Thoracic and Cardiovascular Surgery, Saga Medical School, 5-1-1 Nabeshima, Saga City, Saga 849, Japan.

J Thorac Cardiovasc Surg 1997;114:141-2

Copyright (C) 1997 by Mosby-Year Book, Inc.

$0022-5223 / 97 \$ 5.00+0 \quad \mathbf{1 2 / 5 4 / 8 0 0 9 5}$
One of the patients was a 70-year-old man who was admitted for the treatment of an enlarged ascending aortic aneurysm. Preoperative findings eliminated Marfan syndrome and other degenerative connective tissue disease. A computed tomographic scan of the chest showed the maximum diameter of the aortic aneurysm to be 60 $\mathrm{mm}$, and aortography revealed severe aortic regurgitation. Transesophageal echocardiography showed the nondilated aortic anulus with massive central regurgitation. Thus the cause of the regurgitation was suspected to be dilatation of the sinotubular junction.

An operation was performed through a median sternotomy. A two-staged single venous cannula was inserted into the right atrium. The left femoral artery was cannulated as the arterial line. Cardiopulmonary bypass was initiated and the systemic temperature was reduced to $26^{\circ} \mathrm{C}$. After crossclamping of the aorta, a flexible electric laparoscope (Fujinon Video Laparoscope Systems, Fujinon, Saitama, Japan), the tip diameter of which was $10.3 \mathrm{~mm}$, was inserted into the ascending aorta. One liter of crystalloid cardioplegic solution was infused into the root, and the aortic root was then visualized with an endoscope. This

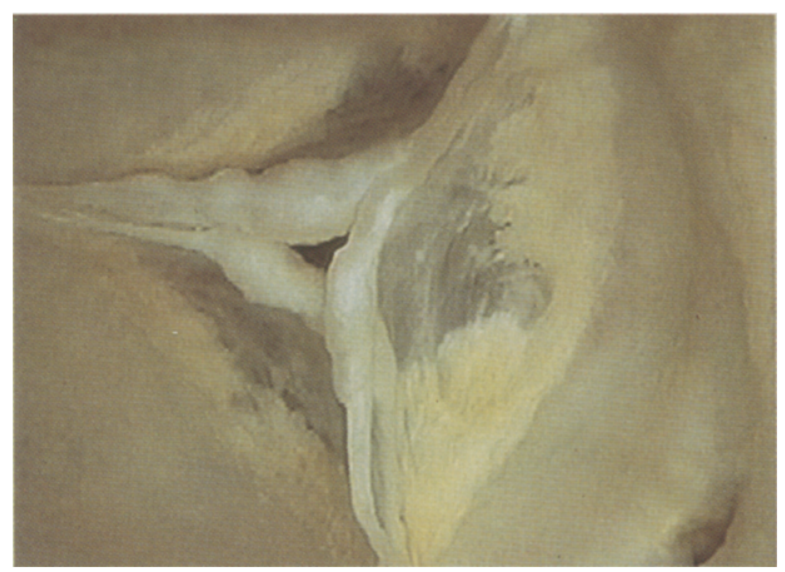

Fig. 1. Endoscopic findings before repair in the patient. Central malcoaptation was found. No organic change was found except slight thickening in the leaflet edge. 